\title{
Impairment of cytomegalovirus and host balance in elderly subjects
}

\author{
MONICA MUSIANI, MARIALUISA ZERBINI, DANIELA ZAULI, ${ }^{*}$ G COMETTI, $\dagger$ \\ M LA PLACA
}

From the Institute of Microbiology, ${ }^{*}$ Institute of Clinical Medicine, and †Division of Geriatrics VI. University of Bologna, Italy

SUMMARY The titres of IgG antibody against "late antigens", "immediate early antigens", and "early antigens" induced by cytomegalovirus (CMV) and IgM antibody against "late antigens" induced by CMV were analysed in 67 geriatric subjects by immunocytochemical techniques. T? titres obtained were compared with those of an adult control population. Significantly increased titres of IgG antibody against induced antigens and a significant increase in CMV reactivated infections occurred in the elderly compared with control subjects.

These findings indicate that the CMV and host balance in the elderly is disturbed, leading to activation of the CMV latent carrier state that follows primary CMV infection.

Cytomegalovirus (CMV) is a member of the herpesviridae family. Although it can cause illnesses ranging from congenital malformations to serious complications in severely immunocompromised hosts, most infections occur asymptomatically, and by adulthood most people have serum antibodies to $\mathrm{CMV}$, which are markers of prior infection. Like other herpes viruses CMV is able to remain latent in those infected with it until an appropriate stimulus or a lowering of immune barriers, or both, reactivates the virus.'

Many studies on man and animals have shown that the efficiency of the immune system declines with age, and it has been suggested that in the elderly the responsiveness of the $T$ cell mediated immune system, both in the effector and in the regulatory compartments, is impaired. ${ }^{2-4}$

Cellular immunity has a major role in the control of viral infections, especially herpes virus infections, and the aim of our study was to see if the impaired immune response in the elderly can activate the latent persistent carrier state that regularly follows primary CMV infection.

\section{Material and methods}

Serum samples were collected from 67 subjects (41 men, 26 women) aged from 70 to 92 (mean 79) years who lacked antinuclear antibody and rheumatoid factor in their sera. They were inpatients admitted mainly for cerebrovascular problems related to age,

Accepted for publication 3 March 1988 and without evidence of malignant, haematological, endocrine, infectious or immunological disorders. As a control population, 67 sex-matched blood donors aged from 25 to 38 (mean age 33) were tested.

The following determinations were made in each serum sample: (i) IgG against "immediate early antigen" (IEA) induced by CMV; IgG against "early antigen" (EA) induced by CMV; (iii) IgG against "late antigen" (LA) induced by CMV; and (iv) IgM against LA induced by CMV. A serological sign of active or recent infection was the concomitant presence of a titre of IgG anti-CMV induced LA of $\geqslant 1 / 320$, antiEA of $\geqslant 1 / 20$, and anti-IEA of $\geqslant 1 / 20$; or the presence of IgM against CMV-induced LA of $\geqslant 1 / 20$. $^{5-6}$

To prepare IEA induced by CMV, human embryo fibroblasts infected with the Towne strain of CMV and grown on coverslips were fixed in acetone one hour after infection. EA induced by CMV were prepared by fixing cells infected in the presence of $75 \mu \mathrm{g} / \mathrm{ml}$ of cytarabine, 72 hours after infection, to accumulate all EA synthesised before replication of viral DNA. LA induced by CMV were obtained by fixing infected cells 72 hours after infection. ${ }^{7}$ Two reference sera were used to test antigen preparations: (BE 184, anti-LA titre 1/ 640, anti-EA titre 1/320, anti-IEA titre 1/160; CF 387, anti-LA titre $1 / 320$, anti-EA and anti-IEA negative titres).

An immunoalkaline phosphatase assay for the detection of IgG to LA induced by CMV, EA, and IEA was performed as previously described ${ }^{8}$ Briefly, acetone fixed cells were treated with serial twofold dilutions of sera at $37^{\circ} \mathrm{C}$ for 45 minutes. After three 
washes in phosphate buffered saline (PBS) alkaline phosphatase labelled goat immunoglobulins to human immunoglobulin $G$ were added. Cells were then incubated at $37^{\circ} \mathrm{C}$ for 45 minutes; after a further three washes in PBS the alkaline phosphatase substrate was added. The alkaline phosphatase label was developed with a naphthol salt as a coupling agent and a diazonium salt (fast blue) as a capture agent, forming an insoluble dark blue precipitate at the site of enzyme localisation.

The presence of $\mathrm{CMV}$-induced $\mathrm{Fc}$ receptors in infected cells did not interfere with our IgG assays, because Fc receptors are concentrated in the perinuclear region of the cytoplasm while IEA and EA have a nuclear localisation and LA have a nuclear:cytoplasmic distribution.

IgM anti-LA induced by CMV were also titrated by immunoalkaline phosphatase assay. Undiluted serum samples were absorbed with Staphylococcus protein A to remove IgG. This pre-treatment avoided the competition of anti-CMV LA IgG molecules with specific IgM in the binding to the antigenic sites. Moreover, this pre-treatment avoided the interference of rheumatoid factor: the removal of IgG from test samples avoids IgM false positive reactions or falsely raised titres of IgM antibody due to the presence of rheumatoid factor.

Serially diluted, absorbed sera were incubated with antigen preparations for three hours at $37^{\circ} \mathrm{C}$. Cell smears were carefully washed, monoclonal antibody to human IgM was added, and a second incubation was performed at $37^{\circ} \mathrm{C}$ for 45 minutes. ${ }^{6}$ After three washes in PBS a further incubation with alkaline phosphatase conjugated immunoglobulins to mouse IgG was carried out, and the reaction was developed as described above.

The significance of results was determined with the $\chi^{2}$ test and with Student's two-tailed $t$ test.

\section{Results}

The distribution of IgG antibody titres against LA, EA, and IEA induced by CMV in 67 elderly people and in the control population is shown in fig 1 . All 67 were seropositive for IgG anti-CMV-induced LA; 55 of the control population (82.0\%) had IgG anti-LA. Thirty nine of the $67(58.0 \%)$ had anti-LA IgG with titres of $\geqslant 1 / 320$; only $10(18.0 \%)$ of the 55 positive control subjects had values of $\geqslant 1 / 320$.

The geometric mean titre of IgG anti-LA in the elderly was $1 / 245$ with a $95 \%$ confidence interval between $1 / 188$ and $1 / 309$. The mean titre of IgG antiLA was 1/79 in CMV positive control subjects with a $95 \%$ confidence interval between $1 / 60$ and $1 / 105$. Statistical analysis with Student's $t$ test gave a $t$ value of $5.645(\mathrm{p}<0.001)$ for both groups.

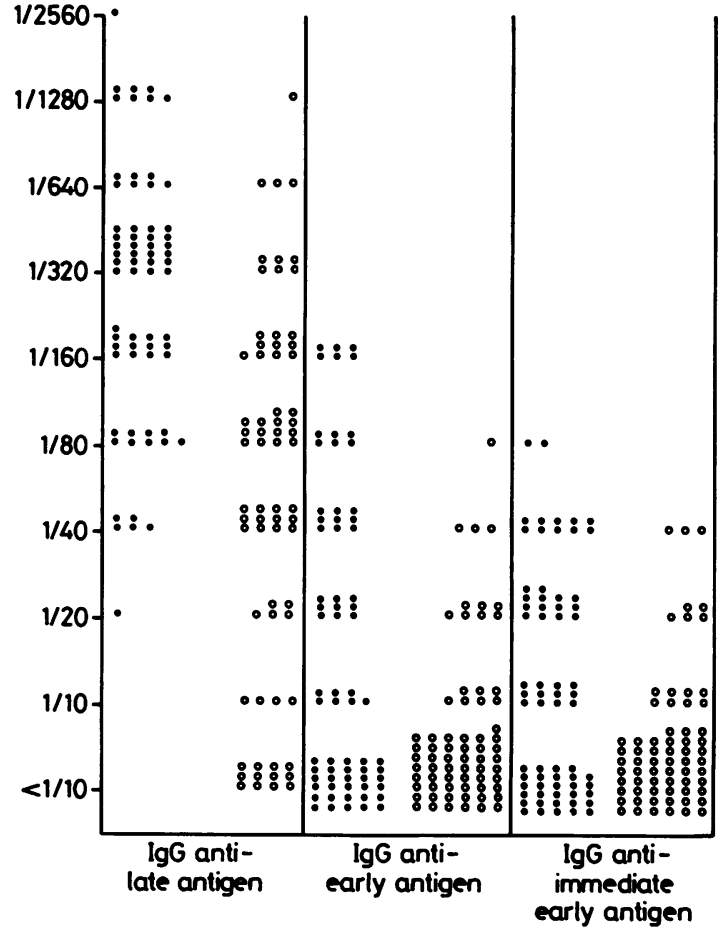

Fig 1 Distribution of $\operatorname{Ig} G$ against $L A, E A$, and IEA induced by $C M V$ in 67 elderly subjects (O) and 67 adult control subjects $(O)$.

Antibodies against EA induced by $\mathrm{CMV}$ were present with titres of $\geqslant 1 / 20$ in 30 old subjects $(45.0 \%)$, compared with 11 of the $55(20 \%)$ control CMV positive subjects $(p<0.01)$. Twenty six elderly subjects $(39 \%)$ had titres against IEA of $\geqslant 1 / 20$, only eight of $55 \mathrm{CMV}$ positive control subjects $(14.5 \%)$ had antibody against IEA $\geqslant 1 / 20(p<0.01)$.

The distribution of IgM antibody titres against CMV-induced LA is shown in fig 2 . In the elderly population 10 of 67 subjects $(15.0 \%)$ had IgM titres of $\geqslant 1 / 20$ and in the CMV positive control subjects six of $55(11.0 \%)$ had IgM titres of $\geqslant 1 / 20$. The statistical analysis of IgM values did not show significant differences between the elderly and the control populations.

Serological signs of CMV active or recent infection (IgG anti-LA of $\geqslant 1 / 320$, IgG anti-EA of $\geqslant 1 / 20$, IgG anti-IEA of $\geqslant 1 / 20$; or the presence of IgM anti-LA of $\geqslant 1 / 20$ ) were present in 26 elderly subjects $(39 \%)$ and in seven $(13 \%)$ control subjects $(p<0.005)$. No subjects with serological signs of active or recent infection showed raised IgM without concomitant presence of high IgG titres. 


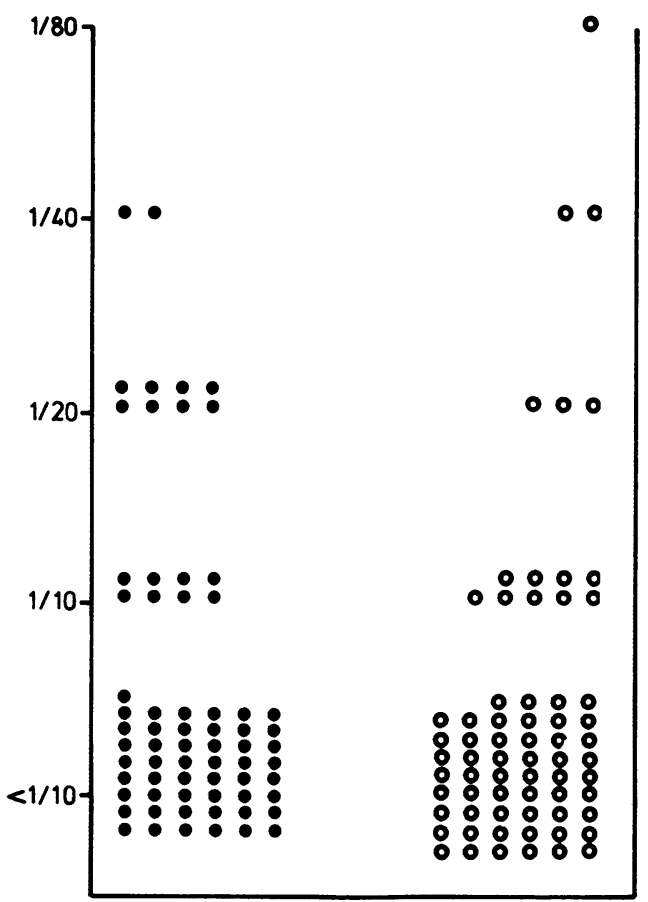

IgM anti-lale antigen

Fig 2 Distribution of IgM against LA induced by CMV in 67 elderly subjects $(\bigcirc)$ and 67 adult control subjects $(O)$.

\section{Discussion}

In the sera of elderly subjects we have shown that there is a significant increase of IgG antibody titres to CMVinduced LA, EA, and IEA and an increased prevalence of CMV recent or active infections compared with adult controls. On the other hand, IgM anti-LA values did not show a significant increase in the elderly. The low positivity and the low titres of IgM in the elderly can be explained by the presence of reactivated and not primary CMV infections. In fact, IgM anti-CMV-LA, which are normally present in primary infections, may or may not be present in CMV reactivations, and then only at very low titres. ${ }^{9}$ In our study all serum samples from the elderly were positive for IgG to LA and presumably the subjects who were CMV-LA positive had been previously infected with CMV.

The high prevalence of CMV reactivated infections in the elderly was similar to that seen in a variety of malignant and benign diseases, all of which have immunosuppressive effects or require immunosuppressive treatment. ${ }^{10-13}$ Our CMV-immune response results in the geriatric population were also consistent with the results obtained by Glaser et al, who studied the immune response against Epstein-Barr virus
(EBV), another member of herpesviridae, which can be reactivated following immunoregulatory defects. ${ }^{14}$ In fact, these authors showed a significant increase of IgG against different antigens induced by the virus in an elderly population compared with a young population. Moreover, given that IgG-1 and IgG-3 are the principal anti-CMV and anti-EBV subclasses in CMV and EBV reactivations, ${ }^{15-16}$ the increased titres of IgG, especially of the IgG-1 and IgG-3 subclasses, shown in elderly people's sera, ${ }^{17}$ could be partly attributed to CMV and EBV reactivations.

In conclusion, our findings suggest that there is a disturbance of the CMV and host balance in the elderly, which could be a consequence of the age related impairment of the cell-mediated immune response. Moreover, the high titres of CMV reactivated infections in the elderly may reflect the development and perpetuation of the atherosclerotic process. Indeed, a recent report confirmed high titres of CMV antibody in clinically manifest atherosclerosis and suggested that periodically reactivated virus may have a role in the pathogenesis of atherosclerosis. ${ }^{18}$

A practical problem, which may also arise from reactivated CMV infection in the elderly, is the prevention of CMV infection acquired through blood transfusions in high risk patients. In view of a reevaluation of the role of the elderly in routine blood donations $^{19}$ we emphasise the need to screen serologically for antibodies against CMV-induced antigens to exclude potential donors with high IgG titres.

The skilful technical help of Ms Marinella Plazzi is gratefully acknowledged. This work was partially supported by Consiglio Nazionale delle Ricerche Progetto Finalizzato Controllo delle Malattie da Infezione, Grant No 87.00651.52 and 87.00611.52.

\section{References}

1 Ho M. Cytomegalovirus. Biology and infection. New York. Plenum Publishing Corporation, 1982.

2 Abe T, Morimoto C, Toguchi T, Kiyotaki M, Homma M. The cellular basis of impaired $\mathrm{T}$ lymphocyte functions in the elderly. $J$ Am Geriatr Soc 1980;28:265-71.

3 Antel JP, Oger JF, Dropcho E, Richman DP, Kuo HH, Aranason BGW. Reduced T-lymphocyte cell reactivity as a function of human aging. Cell Immunol 1980;54:184-92.

4 Murasko DM, Nelson BJ, Silver R, Matour D, Kaye D. Immunologic response in an elderly population with a mean age of 85. Am J Med 1986;81:612-18.

5 Musiani M, Zerbini M, Carpi C, et al. Serological screening for the prevention of transfusion-acquired cytomegalovirus infection. J Infect 1984,9:148-52.

6 Zerbini M, Musiani M, Gentilomi G, La Placa M. Detection of specific immunoglobulin $\mathbf{M}$ antibodies to cytomegalovirus by using monoclonal antibody to immunoglobulin $\mathbf{M}$ in an indirect immunofluorescence assay. J Clin Microbiol 1986;24:166-8.

7 Musiani M, Zerbini M, La Placa M. Alkaline phosphatase immunoenzymatic staining for detection of antigens induced by cytomegalovirus. J Clin Pathol 1985;38:1155-7. 
8 Musiani M, Zerbini M, La Placa M. Rapid diagnosis of viral infections by an alkaline phosphatase immunocytochemical method. J Immunol Method 1986;88:255-8.

9 Wreghitt TG, Gray JJ, Chandler C. Prognostic value of cytomegalovirus IgM antibody in transplant recipients. Lancet 1986;ii:1157-8.

10 Henson D, Siegel SE, Fuccillo DA, Matthew E, Levine AS. Cytomegalovirus infections during acute childhood leukemia. $J$ Infect Dis 1972;126:469-81.

11 Betts RF. Cytomegalovirus infection in transplant patients. Progr Med Virol 1982;28:44-64.

12 Drew WL, Sweet ES, Miner RC, Mocarski ES. Multiple infections by cytomegalovirus in patients with acquired immunodeficiency syndrome: documentation by Southern blot hybridization. $J$ Infect Dis 1984;150:952-3.

13 Musiani M, Zerbini M, Ferri S, Plazzi M, Gentilomi G, La Placa $M$. Comparison of the immune response to Epstein-Barr virus and cytomegalovirus in sera and synovial fluids of patients with rheumatoid arthritis. Ann Rheum Dis 1987;46:837-42.

14 Glaser R, Strain EC, Tarr KL, Holliday JE, Donnerberg RL, Kiecolt-Glaser JK. Changes in Epstein-Barr virus antibody titers associated with aging. Proc Soc Exp Biol Med 1985;179:352-5.
15 Linde GA, Hammarström L, Persson MAA, Smith CIE, Sundqvist VA, Wahren B. Virus-specific antibody activity of different subclasses of immunoglobulins $G$ and $A$ in cytomegalovirus infections. Infect Immun 1983;42:237-44.

16 Linde A, Andersson J, Lundgren G, Wahren B. Subclass reactivity to Epstein-Barr virus capsid antigen in primary and reactivated EBV infections. J Med Virol 1987;21:109-21.

17 Radl J. Effects of aging on immunoglobulins. In: Ritzmann SE, ed. Pathology of immunoglobulins: diagnostic and clinical aspects. Protein abnormalities. New York, Alan R Liss Inc, 1982:55-69.

18 Adam E, Probtsfield JL, Burek J, et al. High levels of cytomegalovirus antibody in patients requiring vascular' surgery for atherosclerosis. Lancet 1987; ii:291-3.

19 Pindyck J, Avorn J, Kuriyan M, Reed M, Iqbal MJ, Levine SJ. Blood donation by the elderly. Clinical and policy considerations. JAMA 1987;257:1186-8.

Requests for reprints to: Monica Musiani, Institute of Microbiology, Via Massarenti 9, 40138 Bologna, Italy. 